\section{Pisotriquetral arthritis: 'forgotten' joint in ultrasound imaging of the wrist}

We read with great interest the study of Di Matteo et al, ${ }^{1}$ which highlighted the association between ultrasound (US)-detected subclinical synovitis and bone erosion with the development of inflammatory arthritis. We agree with the authors that the second and fifth metacarpophalangeal joints and the fifth metatarsophalangeal joints are the most frequent site of US-detected bone erosion. ${ }^{2}$ However, MRI studies have reported that in rheumatoid arthritis (RA), carpal joints were affected by synovitis and erosions more frequently than metacarpophalangeal joints. ${ }^{34}$ The ulnar aspect of the radiocarpal joint and the pisotriquetral joint (PTJ) are the most involved by synovitis. ${ }^{5}$ Moreover, triquetrum is among the most frequent erosion-affected bone ${ }^{3}$ and, according to a recent MRI investigation, seems to be the first morphological site to be affected by RA. ${ }^{4}$

PTJ is a small joint of the ulnar side of the wrist communicating with the radiocarpal joint in $75 \%-85 \%$ of the cases (figure 1A). PTJ disorders are often neglected in clinical practice, ${ }^{6}$ and its evaluation was not taken into account by EULAR standard US assessment of the wrist. ${ }^{7}$

Figure 1B-D shows the sonographic findings in a patient with RA complaining of wrist pain related to PTJ synovitis and triquetral erosion. In order to achieve an optimal PTJ assessment, the operator should start with the EULAR W45 scan (ie, axial volar scan of the wrist at the level of the proximal carpal tunnel) shifting the transducer medially, over the ulnar side of the wrist. In this view, the recess of the PTJ appears small even if there is a synovitis (figure 1B). The orthogonal scan makes it possible to assess the longitudinal PTJ profile: gradually shifting the transducer allows the visualisation of the pisiform (figure 1C) and the triquetrum bone cortex (figure 1D).

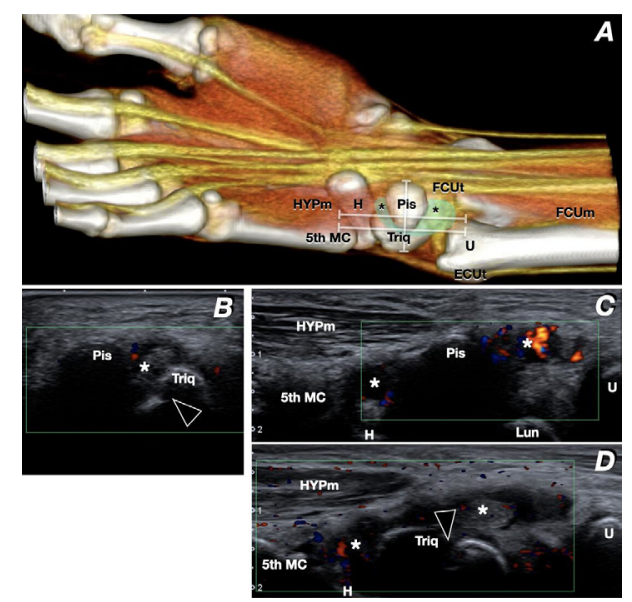

Figure 1 PTJ synovitis and Triq erosion in a patient with RA. (A) CT 3D schematic drawing of a distended PTJ (asterisks). Grey lines indicate the positions of the probe. (B) Axial directional power Doppler sonogram demonstrates synovitis of the PTJ. The recess is small, bulging between the Pis and the Triq. Note a small cortical erosion of the Triq (arrowhead). (C,D) Longitudinal directional power Doppler sonograms at the level of the Pis (C) and Triq (D) better delineate PTJ synovitis and confirm Triq erosion. Fifth MC indicates the fifth metacarpal bone. ECUt, extensor carpi ulnaris tendon; FCUm, flexor carpi ulnaris muscle; FCUt, flexor carpi ulnaris tendon; $\mathrm{H}$, hamatum; HYPm, hypotenar muscle; Lun, lunatum; Pis, pisiform; PTJ, pisotriquetral joint; Triq, triquetrum; U, ulna.
Depending on anatomical variability and grade of joint distension, the articular recess may also be detected in the EULAR W36 scan (longitudinal view of the flexor carpi ulnaris).

In conclusion, we suggest that adding scanning of PTJ could improve US assessment of the wrist and may help in detecting synovitis and erosions in early inflammatory arthritis. We are aware that US has limitations in particular evaluating the more radial part of the triquetrum, for which MRI is the best choice, if clinically indicated. ${ }^{6}$

\section{Andrea Becciolini $\odot,{ }^{1}$ Alarico Ariani $\odot,{ }^{1}$ Marco Becciolini ${ }^{2,3}$ \\ ${ }^{1}$ Department of Medicine, Internal Medicine and Rheumatology Unit, Azienda Ospedaliero-Universitaria di Parma, Parma, Italy \\ ${ }^{2}$ Misericordia di Pistoia, Pistoia, Italy \\ ${ }^{3}$ Scuola SIUMB di Ecografia Muscolo-Scheletrica, Pisa, Italy}

Correspondence to Dr Andrea Becciolini, Department of Medicine, Internal Medicine and Rheumatology Unit, Azienda Ospedaliero-Universitaria di Parma, Parma 43126, Italy; beccio@yahoo.it

Contributors All authors were involved in conception, drafting or revising the article critically for important intellectual content. All authors approved the final version to be submitted for publication.

Funding The authors have not declared a specific grant for this research from any funding agency in the public, commercial or not-for-profit sectors.

Competing interests $A B$ served as a speaker for Abbvie, Amgen, Sanofi-Genzyme and $U C B$, outside the submitted work. MB and AA declared no conflict of interest.

Patient and public involvement Patients and/or the public were not involved in the design, conduct, reporting or dissemination plans of this research.

Patient consent for publication Not required.

Provenance and peer review Not commissioned; internally peer reviewed.

(C) Author(s) (or their employer(s)) 2020. No commercial re-use. See rights and permissions. Published by BMJ.

\section{Check for updates}

To cite Becciolini A, Ariani A, Becciolini M. Ann Rheum Dis Epub ahead of print: [please include Day Month Year]. doi:10.1136/annrheumdis-2020-217980

Received 14 May 2020

Accepted 15 May 2020

\section{(5) Linked}

- http://dx.doi.org/10.1136/annrheumdis-2020-218036

Ann Rheum Dis 2020;0:1. doi:10.1136/annrheumdis-2020-217980

ORCID iDs

Andrea Becciolini http://orcid.org/0000-0002-1051-8511

Alarico Ariani http://orcid.org/0000-0003-1428-6102

\section{REFERENCES}

1 Di Matteo A, Mankia K, Duquenne L, et al. Ultrasound erosions in the feet best predict progression to inflammatory arthritis in anti-CCP positive at-risk individuals without clinical synovitis. Ann Rheum Dis 2020:annrheumdis-2020-217215.

2 Tămaş M-M, Filippucci E, Becciolini A, et al. Bone erosions in rheumatoid arthritis: ultrasound findings in the early stage of the disease. Rheumatology 2014;53:1100-7.

3 Østergaard M, Møller Døhn U, Duer-Jensen A, et al. Patterns of magnetic resonance imaging bone erosion in rheumatoid arthritis--which bones are most frequently involved and show the most change? I Rheumatol 2011;38:2014-7.

4 Larios-Forte MDC, García-Coronado JM, Skinner-Taylor CM, et al. The very early inflammatory triquetral lesion by MRI - is this the first sign in Rheumatoid Arthritis? Acta Reumatol Port 2019;44:218-24.

5 McQueen FM, Stewart N, Crabbe J, et al. Magnetic resonance imaging of the wrist in early rheumatoid arthritis reveals a high prevalence of erosions at four months after symptom onset. Ann Rheum Dis 1998:57:350-6.

6 Moraux A, Lefebvre G, Pansini V, et al. Pisotriquetral joint disorders: an underrecognized cause of ulnar side wrist pain. Skeletal Radiol 2014;43:761-73.

7 Möller I, Janta I, Backhaus M, et al. The 2017 EULAR standardised procedures for ultrasound imaging in rheumatology. Ann Rheum Dis 2017;76:1974-9. 